\title{
Developing Effective Media Relations for Your County Program ${ }^{1}$
}

\author{
Ricky Telg and Lisa Lundy²
}

The news media - radio, television, newspaper, magazines, and other outlets - are one of your best ways of getting news and information about your county program to the public, to citizens. It's feasible to have a mutually beneficial relationship with your local media outlets. You need their help in reaching your community members and they need your help; good stories they receive from you help them stay in business.

Developing an effective news media relations plan can accomplish the following:

- Enhance the public's knowledge and understanding of your county program. It keeps your message in front of leaders and decision-makers.

- Build credibility in your county program; people perceive what they see in the media as important.

- Extend the reach and increase the frequency of your message. Using the media may mean your message reaches people in your community, the state, or around the world. The extended reach helps build self-confidence and pride in your program.

However, media relations cannot:

- Eliminate negatives. Bad news is bad news. If something has put your county program in a bad light, media relations won't eliminate negatives. However, it can help accentuate positives.
- Eliminate the competition. Other organizations may do what you do. You won't be able to get rid of competitors.

- Control the media or the media's message. You do not own the television station; you don't have editorial control of what the station says.

- Be a "quick fix." If something's "broke" in your county program, media relations will not be able to "fix" it. But you can use the media to tell your story.

At this point, maybe it would be good to describe what the news media do. The media pass information to target audiences. They act as filters. They decide what's important and what is actually reported. You also must keep in mind that media are in business for profit. They stay in business by selling advertisement space and, sometimes, through subscriptions. These sales are generated by producing content their audiences want. And where do they get this "good content"? Some of it comes from people like you who have developed an effective media relations strategy.

Try this yourself... Determine how contacting the media would promote your county program or product. How would working with the media help?

\section{Developing a Media Relations}

\section{Strategy}

You must develop a strategy in order to build an effective relationship with the media. It doesn't happen by itself. You

1. This document is AEC339, one of a series of the Department of Agricultural Education and Communication, UF/IFAS Extension. Original publication date April 2000. Revised June 2021. Visit the EDIS website at https://edis.ifas.ufl.edu for the currently supported version of this publication.

2. Ricky Telg, professor, and Lisa Lundy, professor, Department of Agricultural Education and Communication, UF/IFAS Extension, Gainesville, FL 32611.

The Institute of Food and Agricultural Sciences (IFAS) is an Equal Opportunity Institution authorized to provide research, educational information and other services

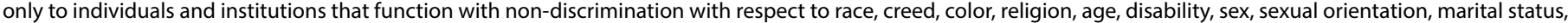

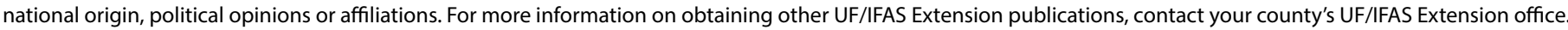
U.S. Department of Agriculture, UF/IFAS Extension Service, University of Florida, IFAS, Florida A \& M University Cooperative Extension Program, and Boards of County Commissioners Cooperating. Nick T. Place, dean for UF/IFAS Extension. 
have to be proactive. Here are suggestions as you map out your plan:

- Set goals and decide on your approach. It's probably unrealistic to expect that every news release you send out will result in a front-page story. But what do you expect? Set realistic goals. Maybe one story a month? Maybe being placed on the community calendar? You also must consider how you will get this done. Through news releases? Personal visits to reporters? On-air interviews?

- Decide who in your office is responsible for media contacts. This may be one person or several. You may wish that one person be the "point" person for all media contacts, or you may wish for a reporter to speak directly to the county faculty member who covers the topic area the reporter has a question about. In either case, you must decide how media contacts will be routed in your office. And this routing system must be known by all persons in your office.

- Become a reputable and dependable expert source. Get to be recognized in your community as the expert in a particular topic or topics. This may result from presentations, relating to your area of expertise, made to civic groups or from assistance you provide to community organizations. If reporters trust you and know that you are an expert in a particular subject matter area, you will be called on regularly for comments.

- Develop a source book of experts in your geographic area and/or in your subject-matter area. Keep track of other experts and sources in the area to whom you could direct reporters if the need arose. You also may wish to supply reporters with this source book.

- Develop a media source book for your office. Keep a directory of reporters and other contacts at the media outlets in your area. Find out what the "rules" are for submitting materials to the media, and enter that information in your media source book. This list must be kept updated.

- Provide materials to reporters on a regular basis. For example, send news releases, public service announcements (PSAs), photographs, and, if there is a subject you have a strong opinion on, a letter to the editor.

- Get to know the reporters in your geographic area, and know the "beat" assignments of reporters. Who covers your "beat" (education, agriculture, business)? Contact the reporters personally, and follow-up with phone calls, faxes, letters, and personal visits. If you read and enjoy a reporter's story, reach out and let him/her know. Building relationships is a critical element of working with the media.

Try this yourself...

Implement each of the suggestions listed in the previous section. For example, decide whom the contact person or persons should be in your office. Make sure everyone in your office knows what to do when a reporter calls. By completing each suggestion noted earlier, you'll be on your way to developing an effective media relations plan.

\section{Understanding the News Media}

One of the components to an effective media relations strategy is to become a reputable, expert source. This also means that you should contribute news items to the media to let them know what's going on in your subject-matter field or your county program. However, what you may consider to be news may not be what news directors consider news. Following are the criteria many news directors use to determine newsworthiness:

- Is the information significant?

- How many readers/viewers could benefit from it?

- Is the story timely?

- Is it local or does it have local impact?

- Is the information accurate?

- Is the information new or different?

With these criteria in mind, you may wonder what story ideas you might have that would be of interest to a news outlet. If you want a reporter to cover a meeting your organization is conducting, you first should ask yourself, "Why would a reporter cover this meeting?" If it is a regular meeting and nothing new or exciting is happening, the chances are slim that the reporter would be interested in covering the meeting. If, however, you have invited a special speaker or are doing something "out of the ordinary," it is very likely a reporter would come. If an important new policy is being discussed, a reporter is likely to come. But notice that the slant of the story would be to cover the "newness" of the event in the meeting, not the meeting itself. 


\section{What to Know about News}

\section{Gathering}

As you can see, one way to establish successful media relations is to think like a reporter. Following are some ideas you must keep in mind when dealing with reporters:

- Scheduling: Other events are happening; make YOURS count! If you know one of the most popular and longestrunning events in the county is going to happen next weekend, don't schedule your activity at the same time as this "sure-fire" news coverage event.

- Provide access to events: Consider offering a virtual option for your event or gathering for a reporter to follow. Help them secure parking, if necessary. Consider any barriers that might keep them from being able to attend.

- Know the reporters' deadlines: Remember that reporters have deadlines to get stories in by. Arrange your news events so they can be covered well in advance of a reporter's deadline. If it doesn't get covered today, it won't be aired the next day. News is news today, not tomorrow. Here is some more information about deadlines: For local TV reporters, the typical story will be shot, edited and aired the same day. To meet TV's deadlines, try to schedule mid-morning or early afternoon shoots. Newspaper deadlines are more flexible, but don't schedule an event too late in the evening if you want it in the next morning's paper. Reporters often share live via social media while covering events. Some of those posts will be part of their ultimate story.

- Reporters are generalists, not specialists. Reporters probably won't know much about a specialized subject. Therefore, reporters need a lot of help when developing a story. They need facts presented clearly and concisely. They don't need unfamiliar acronyms, jargon or technical talk. You may have to do some educating to help the reporter understand the context of your subject.

- Avoid calling news conferences. News conferences should be held only when new and important information needs to get to many media outlets at the same time. For example, don't call a news conference to announce that a new county faculty member has been hired, but do call one if there has been an outbreak of widespread food poisoning and it's imperative that everyone in your county know about the outbreak as quickly as possible. If you call a news conference and there's really no news that comes out of it, reporters won't come in the future when there is real news.
- Determine that the event you want covered by a reporter really is "news." Keep in mind the criteria for newsworthiness detailed in the previous section.

- Reporters are good observers. Anything reporters see or hear is fair game for the story. In other words, do not go "off the record."

- Media like to personalize a story. Submit story ideas that emphasize people.

- Make sure the facts you provide the reporter are correct. If you don't know if something is right or not, don't guess. Check it out before you give it to a reporter. It's acceptable to tell a reporter you'll need to follow up later with additional information.

- Follow trends. Keep up with the events in your own field, and pitch story ideas that are "trendy" or timely. Here's an example if one of your areas of expertise is pets and pet care: If during the holiday season, Dalmatian puppies are the new craze, pitch a story about what people should think about before giving a puppy as a present. Food-related illnesses also are newsworthy. If an outbreak occurs, be ready to call a reporter to discuss proper food handling and preparation.

Finally, here are a few suggestions on how you can help reporters do their jobs better. Remember, if you want to develop good media relations, try to be as accommodating to the media as possible.

- Tip sheets and news releases: These provide reporters with pertinent, accurate information. Providing reporters with other written information, such as brochures or organizational reports, can help reporters tremendously when they write the story.

- Setting: Provide tips on where interviews should be conducted. Most reporters appreciate any tips to enhance a story. What visuals and audio would improve a TV story? You also should avoid noisy offices for interviews. Help reporters find appropriate backgrounds for photographs and television interviews.

- Directions/travel: Provide explicit directions to an event, assistance with camera gear, and help with getting from place to place.

- Several sources/resources: Reporters like to have more than one person to interview. If you know someone who would add to a reporter's story, suggest the person's name. For example, if the story is on a youth livestock program, suggest a local boy or girl who would feel comfortable being interviewed by a reporter. Also suggest printed materials that might be helpful to the reporter. And make 
sure you are the best person to be interviewed. If you're not, try to help the reporter find the best person.

- Understandable terms: No jargon or unfamiliar words.

Try this yourself...

Complete these check-off items each time you submit a story

idea to a reporter.

- Did I develop a tip sheet or news release?

- Did I send the tip sheet or news release?

- Do I have suggestions for good visuals and natural sound (audio)?

- Have I made arrangements for interviews to take place where there is a good background?

- Have I made arrangements for interviews to take place in an area free of distractions (noise, office traffic)?

- Did I send accurate directions to the reporter?

- Can I name other sources who would be helpful to the reporter?

- Can I answer the reporter's questions in a way that's free of technical jargon?

\section{News Releases}

Many times, you will be called upon to write a news release about your county program's activities, interesting news or important events. News releases may accompany letters of correspondence, or they may be distributed to media outlets by themselves. In either case, the content of the news release should stand alone. This means that in case a cover letter is lost, the news release would contain the information a reporter needs to follow-up on the story.

Basically, a news release provides reporters with the basics they need to develop a news story. In large cities, TV stations and newspapers receive dozens of news releases a day. Here are some suggestions to get better play from your news release.

- Target smaller newspapers, TV stations or radio stations. They are more apt to use "community" news.

- Send the release to a particular person at a media outlet. Don't just send it to the "Editor." Send it so a "somebody" (and make sure you spell the person's name correctly). It's a good idea to send the release to the person who most likely would cover the event, for example the business writer, agricultural reporter, or youth and community affairs correspondent.

\section{News Release Formats}

You can write your news release in one of two formats: tip sheet or news story. Some people will combine the two formats and have a tip sheet at the top of a news release and a more detailed news story at the bottom.

The tip sheet presents the reporter's six basic questions in an easy-to-read format. The six questions are referred to by the news media as the 5 W's and $\mathrm{H}$ for "who, what, when, where, why and how." In this format, you would write the following:

Who: Organization's (or person's) name

What: What's going on?

When: When is the event?

Where: Where is the event taking place?

Why: Why is the event taking place?

How: How is the event significant/important?

The news story format is written in just the same way that reporters write news stories, and it provides more details than the tip sheet format. News story format releases are frequently used in newspapers and magazines in the exact form that they were sent in as (especially if it's a small-circulation newspaper or magazine), with little or no editing. This format tends to be longer than the tip sheet.

If you do write a news story format news release, you should emulate newswriting style. Here are some elements of newswriting style to keep in mind:

- Lead-The first paragraph. It is used to grab the reader's attention.

- 5 W's and H-The most important of the questions should be answered in the lead. Others are answered later in the story.

- Short paragraphs-Paragraphs run one to two sentences in length. Rarely do you see paragraphs of more than three sentences.

- Quotations-The exact words of someone talking. It's a good idea to use quotations to bring "life" to your story.

- Inverted pyramid style-You want to include the most important information first (usually what is going on), followed in descending order by less-important information.

Regardless of the format you choose, your news release must identify a contact person and that person's phone number at the top of the news release. It's also a good idea to list the writer of the release as a contact person. Reporters will call a contact person for more information. Let the contact person know they are listed so they can be prepared and available for questions. 
Try these yourself...

Write a tip sheet on an upcoming event in your county program.

Write the same tip sheet information into a news-story format news release.

Send the news release to your local media outlets.

\section{Free Publicity or "Earned Media"}

You may be on a tight budget but would like to stretch your "publicity dollars" as much as you can. In addition to providing media outlets with news releases and tip sheets, here are a few ways to secure earned media:

- Explain your need to local media personally, especially if you need a good deal of exposure in a short time. However, remember that you're asking for free time. Any time that is given to you is better than no time at all.

- Send information about your event to a newspaper or television or radio station's public relations person, public affairs director or promotions director (after you've made personal contact with that person, of course). Many stations have a calendar of events, which is aired once a day. Newspapers tend to list community events once a week.

- Be ready to go on the air early. Many TV and radio stations invite guests to discuss their upcoming events. However, these interviews usually are early in the day. Be ready and willing to appear during early morning hours if you're asked.

- Develop public service announcements (PSAs). Many TV and radio stations air PSAs throughout the day. Radio stations are much better about airing PSAs because they do not take much time to produce. Radio also has more time to fill. They may read the information "live." (Example: "The Tiger Glee Club will sponsor a hay ride Saturday night, starting at 7 . Tickets are $\$ 3$. Proceeds benefit the student scholarship fund. For more information call here at KUFG, Central Florida's choice for news.") Radio and TV announcers usually will help you write the PSA. If you have "live" copy for announcers to read on-air, make sure it is complete. It should have the phone number of someone in your organization to contact. And try to make it as easily readable as possible. Go for a conversational style.

- Maybe send newsletters from your organization. This suggestion is iffy. Newsletters are good ways to get out information about what you're doing, but you should check with reporters before placing them on your newsletter mailing list. You don't want to send newsletters if they are not wanted.

\section{A Final Word}

This fact sheet presented some steps for you to take in order to develop effective relations with media in and around your county. To summarize, get to know reporters in your community, and know their "beat" assignments. Write tip sheets, news releases and PSAs on a regular basis. And most importantly, become a dependable and reputable source. If you accomplish this, you'll find that media relations are not difficult at all. 